\title{
Optimization of the Photochemical Degradation of Textile Dye Industrial Wastewaters
}

\author{
T.H.DANG ${ }^{1}$, , T.P. $\mathrm{MAI}^{2}$, M.T. TRUONG ${ }^{3}$, T.A.N. NGUYEN ${ }^{4}$ AND T.D. LE ${ }^{5}$
}

\begin{abstract}
In this study, the photochemical degradation via photo-Fenton process was carried out to degrade dyes in textile industrial wastewaters. Experimental design methodology was also applied for optimizing effects of factors which influence the effective treatment such as ferric dose, hydroperoxide dosage, initial $\mathrm{pH}$, reaction time and initial chemical oxygen demand (COD). Two independent variables namely colour and COD removal efficiencies were used to evaluate the treatment yield. Under the optimal conditions, ca. $99 \%$ and ca. $88 \%$, colour, and COD were removed, respectively.
\end{abstract}

Key words: Photo-Fenton; textile industrial wastewater; design of experiment

Recently, Vietnam's textile and garment industry are playing a significant role in national socioeconomic development (Agency VTP 2014). However, this sector consumes a lot of water (EPA 1996). Consequently, it is also one of largest groups of industries causing severe water pollution (Torrades \& García-Montaño 2014); they also mentioned that textile mills damaged the quality of the environment by emitting high suspended solids, high temperature, unstable $\mathrm{pH}$, high chemical oxygen demand (COD), low biological oxygen demand (BOD) as well as great colourization (Torrades \& GarcíaMontaño 2014).

On the other hand, textile wastewater usually contains organic compounds which are unable to be degraded by biological or even chemical treatments (Uygur \& Kök 1997; dos Santos et al. 2007) and can be harmful to environments (dos Santos et al. 2007).
Up to now, various methods at the laboratory, pilot or full-scale have been applied for textile wastewater treatment. However, most of them are quite inefficient due to toxic and non-biodegradable substances of textile wastewaters (dos Santos et al. 2007; Forgac et al. 2004). To overcome some drawbacks of currently mentioned methods, researchers focus on advanced oxidation processes (AOPs) such a photo-catalysis method. Typically, Fenton and photo-Fenton techniques which were reported in few published articles have been carried out for treating textile wastewaters (Alinsafi et al. 2007; Lucas \& Peres 2006; Meric et al. 2004; Lee \& Shoda 2008) especially the removal of COD and colourization (Uygur \& Kok 1999; Forgaes et al. 2004; Meric et al. 2004; Lee \& Shoda 2008; Arslan-Alaton et al. 2009) because of their advantages (Torrades \& Garcia-Montana 2014; Arslan-Alaton et al. 2009). Moreover, José Blanco et al. (2012) carried out experiment on textile wastewater via the combination

\footnotetext{
${ }^{1}$ Ho Chi Minh City University of Food Industry, HCMC, Vietnam

${ }^{2}$ Ho Chi Minh City University of Technology - VNU-HCM, HCMC, Vietnam

${ }^{3}$ Mien Trung University of Civil Engineering, Tuy Hoa, Vietnam

${ }^{4}$ Department of Chemistry, Hue University of Sciences, Hue, Vietnam

${ }^{5}$ Thu Dau Mot University, Binh Duong, Vietnam

* Corresponding author (e-mail: dangtanhiep@gmail.com)
} 
of Fenton and biological-Fenton coupled processes. They concluded that Fenton reaction and combination of biological treatment and Fenton reaction were proper treatments to this kind of wastewater. According to the results, Fenton process should be followed by biological treatment for saving energy and cost.

In the experimental point of view, the design of the experiment (DOE) was also employed to find out the optimal conditions of independent variables to overcome some disadvantages of the one-factor-at-a-time method such as more runs, without interaction information or missing optimal setting of factors (Hartmann et al. 2010; Montgomery 2005; Tan-Hiep \& Chen 2013). Therefore, this study presents the application of 2-level fractional factorial design for degrading textile dye wastewater via the photo-Fenton process.

\section{MATERIALS AND METHODS}

\section{Samples and Chemicals}

Characteristics of six loads of textile wastewater (TW) samples gathered from the textile and garment industrial zones in Ho Chi Minh City, and Khanh Hoa Province (Vietnam) were mentioned in Table 1.
COD and colour of all collected samples were analyzed according to fulfill using APHA standards (Standard Methods) (APHA 1998). Other chemicals were also of standard analytical reagents. The taken samples were stored at $4^{\circ} \mathrm{C}$ before use.

\section{Fenton and Photo-Fenton's Reaction}

Fenton's reaction is the dark reaction of ferrous iron $\left(\mathrm{Fe}^{2+}\right)$ with $\mathrm{H}_{2} \mathrm{O}_{2}$. It is a series of reaction to generate $\cdot \mathrm{OH}$ radicals and $\mathrm{Fe}^{2+}$ ion.

$$
\begin{aligned}
& \mathrm{Fe}^{2+}+\mathrm{H}_{2} \mathrm{O}_{2} \rightarrow \mathrm{Fe}^{3+}+\cdot \mathrm{OH}+{ }^{-} \mathrm{OH}(1) \\
& \mathrm{Fe}^{3+}+\mathrm{H}_{2} \mathrm{O}_{2} \rightarrow \mathrm{FeOOH}^{2+}+\mathrm{H}^{+}
\end{aligned}
$$

More recently, some researchers integrate the UV radiation and ozone with Fenton's reaction for treating the toxic wastes (Forgaes et al. 2004; Arslan et al. 2009; Hartmann et al. 2010). The mechanism of the Fenton and photoFenton's reaction Scheme 1 was reported in the published literature (Arslan-Alaton et al. 2009; Sohrabi et al. 2014).

Table 1. Values of colour and chemical oxygen demand of taken textile wastewaters.

\begin{tabular}{c|cc}
\hline Loads & Colour, PCU $^{(\mathrm{a})}$ & COD (ppm) \\
\hline $\mathrm{A}^{(\mathrm{b})}$ & 761.3 & 249.0 \\
$\mathrm{~B}^{(\mathrm{b})}$ & 774.7 & 161.0 \\
$\mathrm{C}^{(\mathrm{c})}$ & $19760-31616$ & $428.8-686.1$ \\
$\mathrm{D}^{(\mathrm{c})}$ & $23712-35568$ & $514.6-772.0$ \\
$\mathrm{E}^{(\mathrm{c})}$ & $33592-41496$ & $729.0-900.5$ \\
$\mathrm{~F}^{(\mathrm{c})}$ & $31616-39520$ & $686.1-857.6$ \\
\hline
\end{tabular}

(a) Platinum-cobalt Unit; (b), (c) Stand for samples taken from industrial zones in Khanh Hoa Province, and Ho Chi Minh City, respectively. 


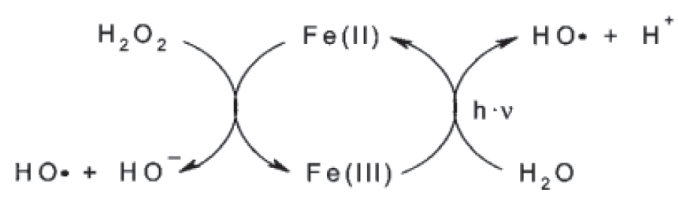

Scheme 1. Mechanism of the photo-Fenton's reaction (Arslan-Alaton et al. 2009).

Kusic H. et al. (2006) mentioned that the Fenton's techniques and a combination of UV and $\mathrm{H}_{2} \mathrm{O}_{2}$ are the widely used methods compared to other chemical AOPs. Therefore, photoFenton in which ferric ion instead of ferrous ion was applied in this case.

\section{Experiments}

In this work, the photo-Fenton's reaction took place in a glass-jacket immersion-type UVreactor which was modified from the system developed by Hansson et al. (2012).

All runs were carried out with a volume of 0.51 of textile wastewaters. All investigated parameters were listed in Table 2, while the unlisted ones such as agitation speed and temperature reaction were kept constant as 400 rpm and ca. $30^{\circ} \mathrm{C}$, respectively. In this case, water was used as a coolant to maintain the reaction temperature constant.

After the desired durations, the $\mathrm{pH}$ value of the treated wastewaters was neutralized to ca. 6.5 and continuously agitated for $5 \mathrm{~min}$ at 400 rpm for quenching the photo-Fenton reaction, while the UV radiation was switched off (Zhu et al. 2011).

\section{Design of Experiment and Statistic Analysis}

According to the published literatures (Uygur \& Kok 1999; Alinsafi et al. 2007; Lucas \& Peres 2006; Meric et al. 2004; Lee \& Shoda 2008; Arslan-Alaton et al. 2009; Hartmann et al. 2010; Sohrabi et al. 2014; Kusic et al. 2006), the main factors or independent variables that can influence the removal efficacy of COD and colour from textile wastewater are initial $\mathrm{pH}$, UV radiation duration (min), dosage ( $\mathrm{mmol}$ ) of $\mathrm{Fe}(\mathrm{III})$ and $\mathrm{H}_{2} \mathrm{O}_{2}$ (HP) as well as the original COD (ppm), while the response variables are removal efficiency of colour (Y1, \%) and COD $(\mathrm{Y} 2, \%)$.

In this report, the fifth batch was selected as a demonstration of the application of design of experiment to do research in environmental issues. Uncoded and coded factors with their

Table 2. The uncoded/coded factors and their concerned levels in this work.

\begin{tabular}{c|ccc}
\hline $\begin{array}{c}\text { Uncoded/ } \\
\text { Coded }\end{array}$ & Name of factors & Low & High \\
& & $(-1)$ & $(+1)$ \\
$\mathrm{pH} / \mathrm{X}_{1}$ & $\mathrm{pH}$ & 3.0 & 4.0 \\
$\mathrm{t} / \mathrm{X}_{2}$ & $\mathrm{UV}$ radiation duration $(\mathrm{min})$ & 30 & 40 \\
$\mathrm{Fe}(\mathrm{III}) / \mathrm{X}_{3}$ & Dosage of Fe(III) (mmol) & 0.75 & 1.0 \\
$\mathrm{HP} / \mathrm{X}_{4}$ & Dosage of $\mathrm{H}_{2} \mathrm{O}_{2}(\mathrm{mmol})$ & 8.0 & 12.0 \\
$\mathrm{COD} / \mathrm{X}_{5}$ & Initial COD $(\mathrm{ppm})$ & 729.0 & 900.5 \\
\hline
\end{tabular}


levels were listed in Table 2.

All statistical analyses, and design of experiment were done by using MS-Excel with calculated appropriate formula were conducted by Montgomery 2005 (Tấn-Hiệp \& Chen 2013) as well as with a statistical software viz. SAS $\mathrm{JMP}^{\circledR}$. The response variables were predicted by using the first-order equation as below in Equation 5.

$$
\hat{Y}=\beta_{o}+\sum_{j=1}^{k} \beta_{j} X_{j}+\sum \sum_{i<j} \beta_{i j} X_{i} X_{j}+\varepsilon
$$

where $k, \hat{Y}, \beta_{j}, \beta_{i j}$ and $\varepsilon$ mean number of independent variables, predicted the response variable, linear regression coefficients, interactive coefficients, and the residual or random error, respectively (Montgomery 2005).

In this study, a two-level fractional factorial design (FFD) for fitting the first-order model expressed as Equation 5, shown in Table 3 was duly carried out. The patterns, the dependent $(Y)$ and predicted $(\hat{Y})$ dependent variables were listed in Table 3, respectively.

The last row in Table 3 describes the average results gained from the experiments conducted at the central point. Also, the run order was randomly performed to minimize errors.

Table 3. The patterns, response and predicted response variables.

\begin{tabular}{c|cccc}
\hline Patterns & $Y_{1}(\%)$ & $Y_{2}(\%)$ & $\hat{Y}_{1}(\%)$ & $\hat{Y}_{2}(\%)$ \\
\hline---+ & 75.6 & 46.7 & 75.6 & 44.9 \\
+---- & 61.8 & 35.9 & 61.8 & 36.6 \\
-+-- & 86.6 & 55.2 & 86.6 & 55.5 \\
+++-+ & 75.0 & 51.7 & 75.0 & 52.5 \\
-+-- & 86.1 & 59.6 & 86.1 & 61.4 \\
++-++ & 78.6 & 55.2 & 78.6 & 54.5 \\
-++-+ & 77.7 & 53.1 & 77.7 & 52.8 \\
++++-- & 87.4 & 60.5 & 87.4 & 59.7 \\
---+- & 97.3 & 64.9 & 97.3 & 64.1 \\
+--++ & 68.7 & 41.0 & 68.7 & 40.7 \\
-+-++ & 90.7 & 60.9 & 90.7 & 60.2 \\
+++-+ & 94.7 & 58.7 & 94.7 & 60.5 \\
--+++ & 92.3 & 62.3 & 92.3 & 63.1 \\
++++- & 65.6 & 29.8 & 65.6 & 30.1 \\
-+++- & 97.0 & 69.3 & 97.0 & 70.0 \\
+++++ & 92.4 & 70.9 & 92.4 & 69.1 \\
00000 & 89.9 & 58.9 & - & - \\
\hline
\end{tabular}




\section{RESULTS}

\section{Examination of Untreated Textile Waste- water}

The taken TWs were characterized by monitoring parameters such as initial $\mathrm{pH}, \mathrm{COD}$, colour, and surfactants, and Table 1 shows the extracted results.

\section{Statistical and Multiple Regression Analysis}

Effects of main factors and interactions. Figure 1 shows the influence of five main factors on the removal efficacy of colour and COD in the case of the fifth batch of TW.

Two first and the fourth variables $\left(X_{1}, X_{2}\right.$ and $X_{4}$ ) would be strongly affected by removal efficiency, while the third and the last one would be of insignificant influence. Therefore, the higher levels of $X_{2}$ and $X_{4}$ the higher efficiencies of both colour and COD removal could be obtained because of their positive linear influence. The influences of $X_{1}$ and $X_{2}$ on the dependent variables are quite similar but in an opposite direction. Typically, the initial $\mathrm{pH}$ value should be decreased to get higher colour and COD removal. Those are also the strongest effects. This statement is consistent with the conclusion of low $\mathrm{pH}$ values as running the Fenton's or photo-Fenton reaction (ArslanAlaton et al. 2009; Hansson et al. 2012).

In the interaction point of view, the highest effect resulted from the interaction between initial $\mathrm{pH}$ and $\mathrm{UV}$ radiation duration $\left(X_{1} X_{2}\right)$ in both colour and COD removal. The effects of the rest are moderate and presented in Table 4. In this case, the higher interactions were neglected because of their insignificant effects. Table 4 expresses an ANOVA analysis for the reduced models at probability of $95.0 \%$.

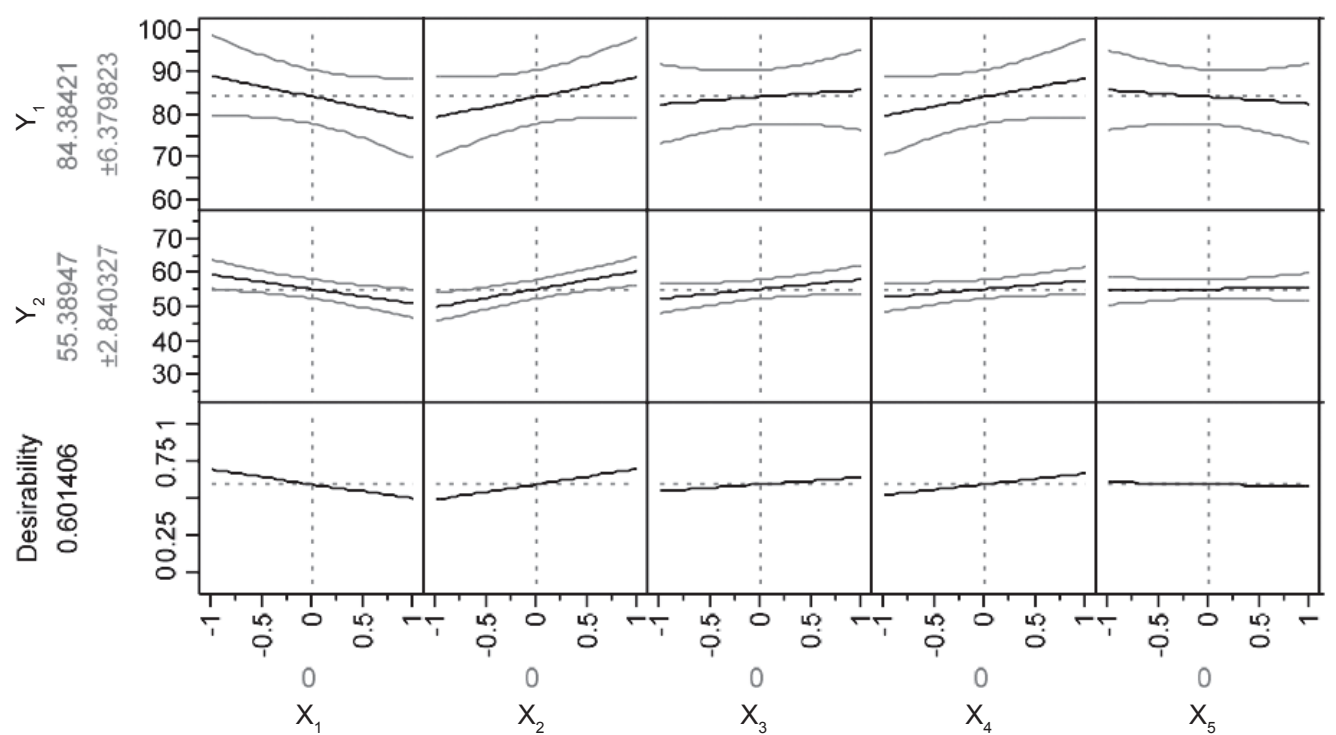

Figure 1. Effects of main factors on response variables. 
Table 4. ANOVA for reduced models.

\begin{tabular}{c|ccccc}
\hline Terms & $|\mathrm{t}|^{(\mathrm{d})}$ & $|\mathrm{t}|^{(\mathrm{e})}$ & Terms & $|\mathrm{t}|^{(\mathrm{d})}$ & $|\mathrm{t}|^{(\mathrm{e})}$ \\
\hline Inter. & 466.4 & 252.8 & $X_{1} X_{4}$ & 11.5 & 13.2 \\
$X_{1}$ & 27.8 & 19.7 & $X_{2} X_{3}$ & - & - \\
$X_{2}$ & 26.5 & 24.5 & $X_{2} X_{4}$ & 9.2 & 11.2 \\
$X_{3}$ & 9.4 & 13.2 & $X_{3} X_{4}$ & 12.3 & 9.3 \\
$X_{4}$ & 24.6 & 11.5 & $X_{1} X_{2} X_{3}$ & - & 4.9 \\
$X_{5}$ & 9.0 & - & $X_{1} X_{2} X_{4}$ & 12.4 & 10.6 \\
$X_{1} X_{2}$ & 26.0 & 21.6 & $X_{1} X_{3} X_{4}$ & 12.1 & 6.4 \\
$X_{1} X_{3}$ & 7.3 & - & $X_{2} X_{3} X_{4}$ & 12.6 & 17.3 \\
\hline
\end{tabular}

(d),(e) Stand for $\mathrm{Y}_{1}$ and $\mathrm{Y}_{2}$, respectively.

The reduced models for colour $\left(\hat{Y}_{1}\right)$ and COD $\left(\hat{Y}_{2}\right)$ are expressed in Equations 2-3, respectively.

$$
\hat{Y}_{1}=82.97-4.94 X_{1}+4.72 X_{2}+1.67 X_{3}
$$$$
+4.37 X_{4}-1.59 X_{5}+4.63 X_{1} X_{2}+1.13 X_{1} X_{3}-
$$$$
2.04 X_{1} X_{4}+1.64 X_{2} X_{4}-2.18 X_{3} X_{4}+2.21 X_{1} X_{2} X_{4}
$$$$
-2.14 X_{1} X_{3} X_{4}+2.24 X_{2} X_{3} X_{4}
$$

$\hat{Y}_{2}=54.73-4.27 X_{1}+5.31 X_{2}+2.86 X_{3}$ $+2.49 X_{4}-0.49 X_{5}+4.68 X_{1} X_{2}-2.86 X_{1} X_{4}+$ $2.42 X_{2} X_{4}-2.01 X_{3} X_{4}+1.06 X_{1} X_{2} X_{3}+2.29 X_{1} X_{2} X_{4}$ $-1.38 X_{1} X_{3} X_{4}+3.74 X_{2} X_{3} X_{4}$
Checking model adequacy. The determine coefficient values, $\mathrm{R}^{2}$, of $99.49 \%$ for decolouration and $99.26 \%$ COD removal meant that not only a good agreement between predicted and observed values but also the obtained mathematical models, Equations 6-7, could predict the removal efficiencies very well (Montgomery 2005; Tấn-Hiệp \& Chen 2013).

Furthermore, $F_{\text {exp. }}$ values of these models were 9.7 and 8.3 respectively. In comparing to $\mathrm{F}_{\alpha, \mathrm{dfl}, \mathrm{dr} 2}$ of 19.0, these models were significant. Hence, they could be used for predicting the experimental results, Figure 2.
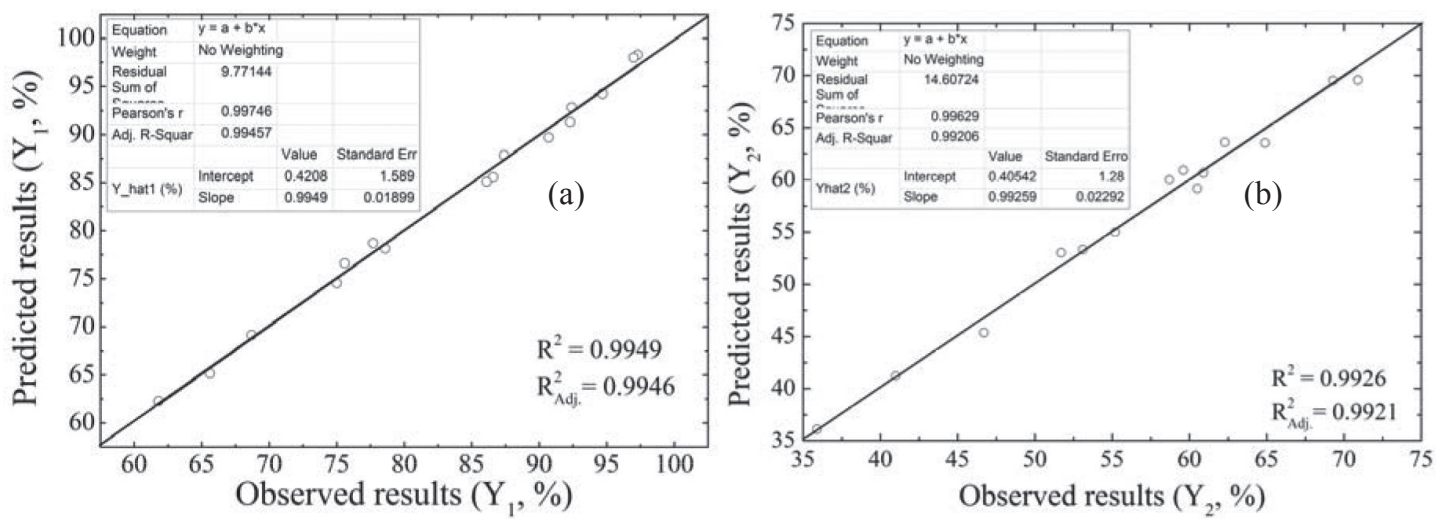

Figure 2. Observed vs. predicted removal efficacies of colour (a) and COD (b). 
Optimization. The analyses obtained above implied that the actual optimum was outside these operating conditions previously investigated. Thus, the steepest ascent method was preferentially called up to find out the optimal operation conditions. The as-fitted multi-linear models shown as Equations 6-7, were used in this paper. The path of the steepest ascent is the line through the center of FFD moving the fastest to the fitted surface. Usually, it will go until no further increment in response is observed (Montgomery 2005; Tan-Hiep \& Chen 2013).

In this study, the optimal condition is 2.70 of initial $\mathrm{pH}$, the duration time of ca. 51 $\mathrm{min}$, and 0.975 and $12.00 \mathrm{mmol}$ of ferric and HP dose, respectively. Under the optimum condition, efficacies of colour and COD removal could be attained as high as of ca. $99.5 \%$ for decolouration and ca. $88.0 \%$ for COD removal.

\section{CONCLUSIONS}

Photo-Fenton's reaction using ferric could be conducted for degrading dyes in textile and garment wastewater collected from an industrial park in Khanh Hoa as well as Ho Chi Minh City (Vietnam).

It could be successful to apply DOE especially FFD for solving not only the specific example in this study (colour and COD removal) but also other problems of environmental engineering.

These optimal conditions were summarized as: (1) initial $\mathrm{pH}$ value of 2.7; and (2) UV radiation duration of ca. $51 \mathrm{~min}$, the dosage of ferric and HP respectively of 0.975 and 12.00 mmol, and stirring speed of $400 \mathrm{rpm}$. The positive point of this study was the quality of treated TW which satisfied the Vietnam National Standards (Type B).

Date of submission: March 2016 Date of acceptance: April 2016

\section{REFERENCES}

Agency VTP 2014, Strengths of the Vietnam textile and garment industry, Vietnam.

Alinsafi, A, Evenou, F, Abdulkarim, EM, Pons, MN, Zahraa, O \& Benhammou, A et al. 2007, 'Treatment of textile industry wastewater by supported photocatalysis', Dyes and Pigments, vol. 74, pp. 439-345.

APHA 1998, Standard methods for examination of the water and wastewater, American Water Works Association, APHA, Washington D.C., Water Environment Federation Publication.

Arslan-Alaton, I, Tureli, G \& Olmez-Hanc, T 2009, 'Optimization of the photo-Fentonlike process for real and synthetic azo dye production wastewater treatment using response surface methodology', Photochem. PhotoBiol. Sci., vol. 8, pp. 628-638.

Blanco, J, Torrades, F, De la Varga, M \& García-Montaño, J 2012, 'Fenton and biological-Fenton coupled processes for textile wastewater treatment and reuse', Desalination, vol. 286, pp. 394-399.

Dos Santos, AB, Cervantes, FJ \& van Lier, JB 2007, 'Review paper on current technologies for decolourisation of textile wastewaters: perspectives for anaerobic biotechnology', Bioresour. Technol., vol. 98, pp. 2369-2385.

EPA 1996, Best management practices for pollution prevention in the textile industry, Washington DC, USA.

Forgac, E, Cserháti, T \& Oros, G 2004, 'Removal of synthetic dyes from wastewaters: a review', Environ. Int., vol. 30, pp. 953-971.

Hartmann, M, Kullmann, S \& Kelle, H 2010, 'Wastewater treatment with heterogeneous Fenton-type catalysts based on porous materials', J. Mater. Chem., vol. 20, pp. 9002-9017. 
Hansson, H, Kaczala, F, Marques, M \& Hogland, W 2012, 'Photo-Fenton and Fenton oxidation of recalcitrant industrial wastewater using nanoscale zero-valent iron', Int. J. Photoenerg., vol. 2012, pp. 11.

Kusic, H, Koprivanac, N \& Bozic, AL 2006, 'Minimization of organic pollutant content in aqueous solution by means of AOPs: UVand ozone-based technologies', Chem. Eng. J., vol. 123, pp. 127-137.

Lee, H \& Shoda, M 2008, 'Removal of COD and colour from livestock wastewater by the Fenton method', J. Hazard. Mater., vol. 153, pp. 1314-1319.

Lucas, MS \& Peres, JA 2006, 'Decolourization of the azo dye Reactive Black 5 by Fenton and photo-Fenton oxidation', Dyes and Pigments, vol. 71, pp. 236-244.

Meric, S, Kaptan, D \& Ölmez, T, 2004, 'Colour and COD removal from wastewater containing Reactive Black 5 using Fenton's oxidation process, Chemosphere, vol. 54, pp. 435-441.

Montgomery, DC 2005, Design and analysis of experiment, 6th edn, New Jersey John Wiley $\&$ Sons, Inc.
Sohrabi, MR, Khavaran, A, Shariati, S \& Shariati, S 2014, 'Removal of Carmoisine edible dye by Fenton and photo Fenton processes using Taguchi orthogonal array design', Arabian J. Chem., in press.

Tấn-Hiệp, Đ \& Chen, B-H 2013, Optimization in esterification of palmitic acid with excess methanol by solid acid catalyst', Fuel Process. Technol., vol. 109, pp. 7-12.

Torrades, F \& García-Montaño, J 2014, 'Using central composite experimental design to optimize the degradation of real dye wastewater by Fenton and photo-Fenton reactions', Dyes and Pigments, vol. 100, pp. 184-189.

Uygur, A \& Kök, E 1997, 'Decolourisation treatments of azo dye wastewaters including dichlorotriazinyl reactive groups by using advanced oxidation method', Colour Technol., vol. 115, pp. 350-354.

Zhu, X, Tian, J, Liu, R \& Chen, L 2011, 'Optimization of Fenton and electroFenton oxidation of biologically treated coking wastewater using response surface methodology', Sep. Purif. Technol. S., vol. 81, pp. 444-450. 